\title{
Activity of calcined coal gangue fine aggregate and its effect on the mechanical behavior of cement mortar
}

Zuochao Dong a,b, Junwu Xia ${ }^{\mathrm{a}, \mathrm{b}^{*}}$, Chao Fan ${ }^{\mathrm{b}}$, Jichang Cao ${ }^{\mathrm{b}}$

a School of Mechanics \& Civil Engineering, China University of Mining and Technology, Xuzhou 221116, PR China.

b Jiangsu Key Laboratory of Environmental Impact and Structural Safety in Engineering ,China University of Mining and Technology, Xuzhou 221116, PR China.

* Corresponding author; E-mail:xiajunw@yahoo.com (J.W. Xia); Tel.: +86 1395229 8267; fax: +8651683995179 


\begin{abstract}
In order to reveal the influence of coal gangue aggregate activity on the mechanical properties of the mortar, to promote coal gangue fine aggregate in concrete mortar application, this paper in view of the calcined coal gangue aggregate carried out ion dissolution test (ICP), construction of the coal gangue aggregate ion dissolution amount and its surface area ratio as a quantitative index of activity, namely activity index of $K a$. The different fineness modulus, different curing age of concrete mortar carried out compressive strength and flexural strength test, and the hardening of cement mortar combined with microscopic test results, in order to analyze the influence of coal gangue aggregate activity on the mechanical performances of mortar. Experimental results show that, under the same calcination temperature and surface area of coal gangue fine aggregate with the same ion dissolution ability, coal gangue fine aggregate index activity increases with the gradual decrease of fineness modulus. A higher activity index of coal gangue fine aggregate mortar corresponds to higher compressive strength and flexural strength of mortar in the improved macro mechanical properties; the early strength of mortar has clear characteristics.
\end{abstract}

Keywords: coal gangue fine aggregate; high-temperature calcination; active index; ion release; mechanical properties 


\section{Introduction}

Coal gangue is produced in the process of coal mining, sorting, and processing of solid wastes, accounting for approximately $10 \%$ of coal production $[1,2]$. A large number of simple piles of coal gangue negatively affected the environment. With the mass production of coal gangue, one way to use it is to replace ordinary sand by coal gangue fine aggregate mixed into concrete, which is called coal gangue fine aggregate concrete. The active $\mathrm{SiO}_{2}$ and $\mathrm{Al}_{2} \mathrm{O}_{3}$ components in the coal gangue, with cement hydration products at a certain degree of secondary hydration reaction, can facilitate a more thorough hydration process and improve the microstructure and macro mechanical properties of cement mortar $[3,4,5]$. For example, F. Salguero et al. [6] have used coal gangue to replace part of the fine aggregate, the experimental tests indicate the fitness of the new material for the purposed application, namely regarding resistance to compression, it reached higher compressive resistance (56.44 $\mathrm{MPa})$, comparatively with the conventional concrete (maximum at $41.03 \mathrm{MPa}$ ). Therefore, the active influence of concrete mortar on the mechanical properties of concrete mortar is analyzed to scientifically and effectively evaluate the activity of coal gangue fine aggregate. Coal gangue utilization has become a major topic related to social and economic development. Many scholars have conducted extensive and in-depth research on coal gangue activity $[7,8,9,10]$. The coal gangue ash evaluation method has the following categories: strength evaluation, evaluation, and electrochemical evaluation of microscopic structure. Many researchers have investigated and practiced these three methods, but the evaluation system has matured only through the quantitative analysis of coal gangue powder material. Application for fineness modulus of large sand body material is not possible. Thus, a deeper quantitative evaluation of the activity of coal 
gangue fine aggregate and building activity as well as its relationship with concrete mortar strength is needed.

This study is based on the engineering application and research background of gangue fine aggregate for the $500,600,700,800$, and $900{ }^{\circ} \mathrm{C}$ high-temperature calcination. Coal gangue by calcination and its phases, which involve a series of changes, contains a large number of active components that can improve the activity of coal gangue $[11,12,13,14]$. XRD diffraction experiment is conducted to analyze the coal gangue fine aggregate activity as it changes with calcination temperature. Then of calcined coal gangue in materials by ion dissolution test (ICP) and specific surface area determination (BET) test, with coal gangue aggregate surface ion dissolution amount and its surface area ratio, as an active quantitative index, activity index $(\mathrm{Ka})$, in order to quantitative assessment of price of coal gangue aggregate activity. ICP (Inductively Coupled Plasma), is a kind of test method used for determination of element concentration, by ICP emission spectrometer, the sample in the Plasma excitation, make specific wavelengths of light that is emitted element under test instrument can analyze the elements of the emission spectrum peak intensity, compared to the mass number of standard curve and standard solution of quantitative analysis of the elements in the solution [15]. BET, it is a standard test method for measuring solid specific surface area, surface tester is based on nitrogen adsorption, with helium or hydrogen as the carrier, two gases mixed in certain proportion, to achieve the specified relative pressure, and then through the solid material, on the basis of the absorption peak area, can be calculated under the pressure of adsorption, which according to BET formula to calculate the specific surface area [16].

At last, combined with the environmental scanning electron microscopy (SEM) analysis, the 
influence of different activity index of coal gangue fine aggregate on the compressive strength and flexural strength of concrete mortar was analyzed.

\section{Experimental section}

\subsection{Coal gangue physical and chemical properties}

The coal gangue from Xuzhou mining area was tested for non-spontaneous combustion. Black or dark gray color indicates higher hardness rate.

Using ordinary concrete to building sand, stone quality inspection standard test method, to $700{ }^{\circ} \mathrm{C}$ high temperature calcined coal gangue core drilling, core samples of the cylinder diameter and height are of $50 \mathrm{~mm}$, after press testing, we can see gangue axial compressive strength of $55.2 \mathrm{Mpa}$, therefore, $700{ }^{\circ} \mathrm{C}$ of calcined coal gangue content of ordinary concrete aggregate demand $[17,18,19]$. The main chemical composition of coal gangue was analyzed by $\mathrm{X}$-ray fluorescence spectrometry (XRF) (Table 1). The coal gangue is composed of $\mathrm{SiO}_{2}, \mathrm{Al}_{2} \mathrm{O}_{3}$, iron, calcium, and magnesium oxide. The indicators of coal gangue utilization were compared according to the condition $\mathrm{SiO}_{2}+\mathrm{Al}_{2} \mathrm{O}_{3}>80 \%$. The chemical composition characteristics are rich in siliceous or aluminum characteristics. The chemical composition of coal gangue is used as fine aggregate concrete [12, 20, 21].

\section{Table 1}

Coal gangue main chemical composition

\begin{tabular}{llllllll}
\hline $\begin{array}{c}\text { Chemical } \\
\text { composition }\end{array}$ & $\mathrm{SiO}_{2}$ & $\mathrm{Al}_{2} \mathrm{O}_{3}$ & $\mathrm{Fe}_{2} \mathrm{O}_{3}$ & $\mathrm{CaO}$ & $\mathrm{MgO}$ & $\mathrm{Na}_{2} \mathrm{O}$ & $\mathrm{K}_{2} \mathrm{O}$ \\
\hline Content $(\%)$ & 59.78 & 29.35 & 1.44 & 0.68 & 0.51 & 0.08 & 1.76 \\
\hline
\end{tabular}

\subsection{Coal gangue fine aggregate activity analysis}


Gangue mineral composition analysis was conducted using X-ray diffractometer. The coal gangue in 500, 600, 700, 800, and $900{ }^{\circ} \mathrm{C}$ temperature was calcined under two hours and rapidly cooled to room temperature. The diffraction experiment was conducted according to the diffraction condition 325 to grind the coal gangue into powder. The test conditions were the following: $40 \mathrm{KV}$ X-ray tube accelerating voltage, $30 \mathrm{~mA}$ electric current, $\mathrm{Cu}$ target, $\mathrm{K}$ radiation, $250 \mathrm{~mm}$ goniometer radius, $0.6 \mathrm{~mm}$ divergence slit, $8 \mathrm{~mm}$ scattering slit, $0.1 \mathrm{sec} / \mathrm{step}$ scanning speed, and 0.018450 sampling interval (step). Calcined coal gangue fine aggregate phase was characterized by types of changes.

\subsection{ICP ion dissolution test and determination of specific surface area}

\subsubsection{ICP ion dissolution test}

The standardized ion dissolution test [22], compared with the standard test, adopts the scaling method, which is the configuration of $\mathrm{NaOH}$ solution (1 g of gangue sample corresponding to $100 \mathrm{~mL} \mathrm{NaOH}$ solution). Several gangue fine aggregate samples were weighed with a corresponding $1 \mathrm{~mol} / \mathrm{L}$ of $\mathrm{NaOH}$ solution in a container. This task was performed after the samples were sealed in a constant temperature box set at $40{ }^{\circ} \mathrm{C}$ for three hours and then filtered; the filtrate was used as preservation seal. Full spectrum direct reading plasma emission spectrometer was used to detect the filtrate $\mathrm{Al}^{3+}$ and $\mathrm{Si}^{4+}$ ion leaching, particularly coal gangue silicon-oxygen tetrahedron and aluminum-oxygen tetrahedron depolymerization ability [23, 24, 25].

2.3.2. Determination of specific surface area (BET)

Surface area analyzer was used to measure the adsorption characteristics of fine aggregate, thereby performing a surface area analysis. The analyzer was equipped with three sample 
measurement channels. Each channel had independent pressure sensors that measured the three samples simultaneously. Coal gangue fine aggregate samples must be dry and have granularity below $5 \mathrm{~mm}$, as well as specific surface area greater than $0.01 \mathrm{~m}^{2} / \mathrm{g}$.

The first gangue fine aggregate was the ICP ion dissolution test. After test completion, the gangue fine aggregate was dried and its surface area was determined using the BET analyzer. The test results are shown in Tables 2 and 3.

\section{Table 2}

Ion dissolution of different fineness modulus values under the same calcinations temperature

\begin{tabular}{ccccc}
\hline Calcination & Fineness & Specific surface & & \\
temperature $\left({ }^{\circ} \mathrm{C}\right)$ & modulus & area $\left(\mathrm{m}^{2} / \mathrm{g}\right)$ & $\mathrm{Al}(\mathrm{mg} / \mathrm{L})$ & $\mathrm{Si}(\mathrm{mg} / \mathrm{L})$ \\
\hline 700 & 1.9 & 9.4799 & 126.76 & 130.11 \\
700 & 2.7 & 6.5557 & 74.44 & 76.23 \\
700 & 3.4 & 4.6464 & 46.81 & 48.07 \\
\hline
\end{tabular}

Table 3

Different calcination temperatures under the same fineness modulus of ion dissolution values

\begin{tabular}{|c|c|c|c|c|}
\hline $\begin{array}{c}\text { Calcination } \\
\text { temperature }\left({ }^{\circ} \mathrm{C}\right)\end{array}$ & $\begin{array}{l}\text { Fineness } \\
\text { modulus }\end{array}$ & $\begin{array}{c}\text { Specific surface } \\
\text { area }\left(\mathrm{m}^{2} / \mathrm{g}\right)\end{array}$ & $\mathrm{Al}(\mathrm{mg} / \mathrm{L})$ & $\mathrm{Si}(\mathrm{mg} / \mathrm{L})$ \\
\hline Original & 2.7 & 6.7314 & 2.54 & 6.69 \\
\hline 500 & 2.7 & 6.7314 & 65.03 & 67.00 \\
\hline 600 & 2.7 & 6.7314 & 72.09 & 72.20 \\
\hline 700 & 2.7 & 6.7314 & 74.44 & 76.23 \\
\hline 800 & 2.7 & 6.7314 & 52.14 & 58.09 \\
\hline 900 & 2.7 & 6.7314 & 0.43 & 28.96 \\
\hline
\end{tabular}




\subsection{Make and strength test specimens}

Portland cement using P.O42.5 cement and tap water. The original fresh coal gangue was crushed, sorted, and calcined. The fineness modulus after the screening was 1.9, 2.7, and 3.4 coal gangue fine aggregate, which were classified under fine, medium, and coarse sand specifications, respectively. Proportion, quality fixed water, and cement have a fine aggregate ratio of 1:2:4. The specimen size has length $\times$ width $\times$ height of $40 \mathrm{~mm} \times 40 \mathrm{~mm} \times 160 \mathrm{~mm}$ according to the standard strength detection method, molding cement mortar specimens [26]. The cement mortar specimens were made in a curing chamber to the required standard curing age.

\subsection{Microstructure analysis (SEM)}

Environmental scanning electron microscopy is the standard method of raising broken specified support age-hardened cement mortar test pieces. The selected test center of a $5 \mathrm{~mm}$ cube small is fragmented after drying. Other procedures terminate the hydration. Moreover, selected pieces were placed in a vacuum-coating machine for evaporation on a layer of gold conductive film, and then under the scanning electron microscope observation of its microstructure.

\section{Results and Discussion}

\subsection{Fine aggregate activity evaluation}

Coal gangue aggregate has an irregular granular body. The subsequent test analysis showed that coal gangue set material in the calcination process mainly exhibited a change of surface mineral composition. These changes in concrete, mortar, and cement occurred as a reaction to hydration. The fine aggregate surface active group was divided into two parts. In ICP ion dissolution testing, the group of hydroxyl ions with $\mathrm{NaOH}$ solution has a chemical reaction on the 
fine material on the surface of the $\mathrm{SiO}_{2}$ and $\mathrm{Al}_{2} \mathrm{O}_{3}$ activity component. Therefore, the set of coal gangue in material active substances are distributed in the surface, internal active substance does not participate in the chemical reaction, the same calcination temperature, the same table area of coal gangue in the material with the same ion dissolution ability, and the quality of the fine aggregates.

According to the literature [27, 28], different calcining temperatures of coal gangue are used in the $\mathrm{NaOH}$ solution. The $\mathrm{Si}^{4+}$ and $\mathrm{Al}^{3+}$ ion dissolution characteristics of the strength and cement mortar are consistent with the variation of coal gangue calcined temperature. Moreover, these characteristics are consistent with the dissolution of active $\mathrm{Al}_{2} \mathrm{O}_{3}$ and $\mathrm{SiO}_{2}$ content, coal gangue volcanic ash activity, and the maximum correlation coefficient. Therefore, in this paper, the ICP ion dissolution test, the test of calcined coal gangue fine material in $\mathrm{NaOH}$ solution of $\mathrm{Si}^{4+}$ and $\mathrm{Al}^{3+}$ ion dissolving out amount, by specific surface area analyzer (BET) determination of the surface area, with coal gangue aggregate surface ion dissolution amount and its surface area ratio, as a quantitative index of activity, activity index $(K a)$.

\subsection{Coal gangue fine aggregate activity analysis}

For the qualitative analysis of coal gangue fine aggregate in the calcining process, the changes of the active component, original state, and calcined temperatures at 500, 600, 700, 800, and $900{ }^{\circ} \mathrm{C}$ were analyzed by XRD. The results are presented in Figure 1 . By the original state and different coal gangue calcined temperature of $\mathrm{X}$ ray diffraction pattern shows that with the increase of calcination temperature, kaolinite began to decompose, quartz diffraction peak gradually strengthen, when up to $700{ }^{\circ} \mathrm{C}$, kaolinite is decomposed completely, quartz reached the highest diffraction peak intensity of active $\mathrm{SiO}_{2}$ and $\mathrm{Al}_{2} \mathrm{O}_{3}$ generation peak, so at this time of the 
coal gangue activity is the highest, as temperatures continue to rise, the active $\mathrm{SiO}_{2}$ and $\mathrm{Al}_{2} \mathrm{O}_{3}$ further generate new minerals, reduce its activity.

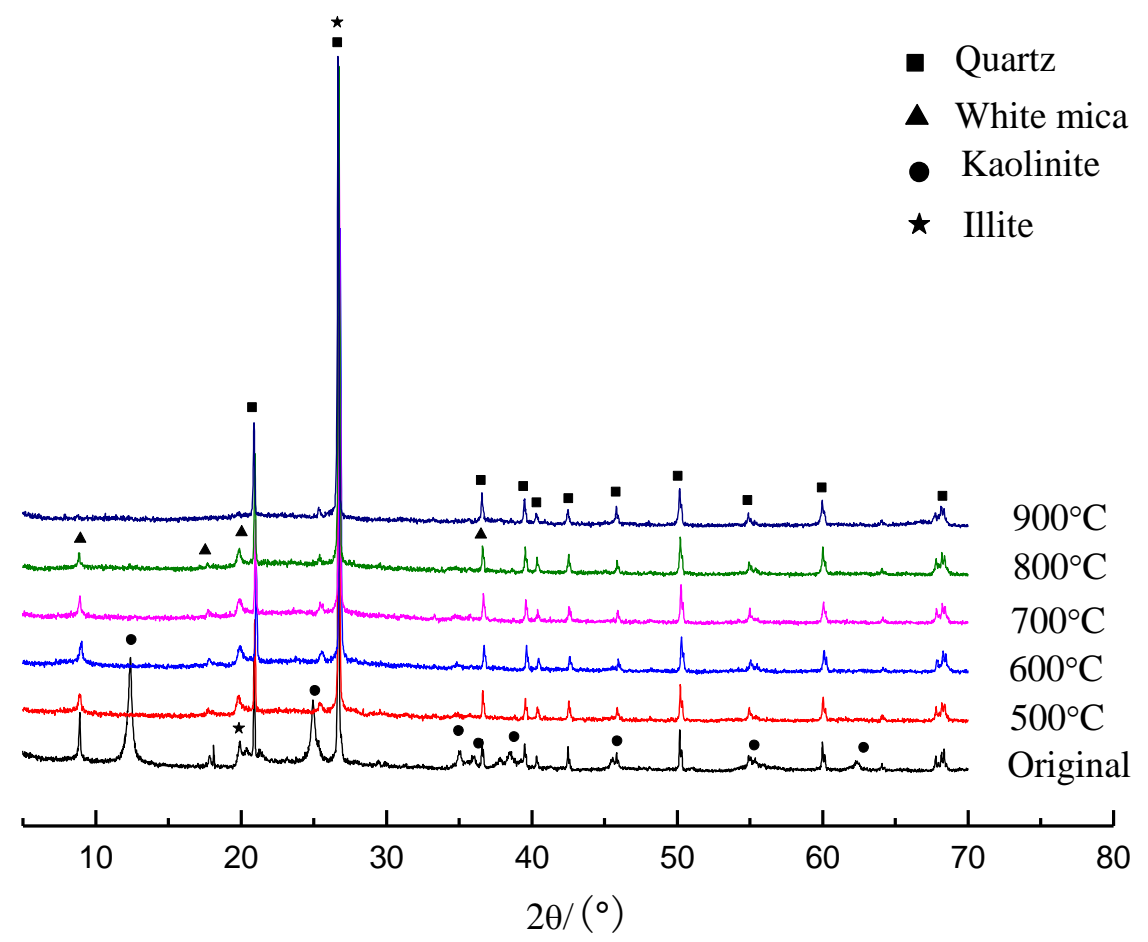

Fig.1 XRD patterns of fine aggregates of coal gangue in original state and different calcination temperatures

\subsection{Same fineness modulus of fine aggregate ion dissolution laws}

Figure 2 shows the fineness modulus of 2.7 gangue fine aggregate in the high-temperature calcination, by ICP ion dissolution test was $\mathrm{Si}^{4+}$ and $\mathrm{Al}^{3+}$ ion leaching sum with calcination temperature curve. And the coal gangue aggregate surface ion dissolution amount and its surface area ratio, namely activity index $\mathrm{Ka}$, showing in the right ordinate axis, between observation activity index $K a$ and calcination temperature changes. ICP ion dissolution test, the $\mathrm{Si}^{4+}$ and $\mathrm{Al}^{3+}$ ion dissolution and the test results of the specific surface area are shown in Table 2 and table 3, respectively. 
In this paper, we use the method to evaluate the activity of coal gangue fine aggregate in the same fineness. The figure 2 shows that with the increase of calcination temperature, $\mathrm{Si}^{4+}$ and $\mathrm{Al}^{3+}$ ion dissolution amount and its surface area ratio $(K a)$, the change rule and the coal gangue powder almost entirely consistent [22]. That with the increase of calcination temperature, the activity of coal gangue also will increase, the peak at $700{ }^{\circ} \mathrm{C}$, when calcining temperature rise further, activity falling.

Mainly because the coal gangue fine aggregate in the process of calcination, volume expansion due to mineral decomposition will be the formation of free material and the fine aggregate particles around the stoma has the effect of filling and extruding, lead to internal mineral aggregate reaction, reaction occurs only on the surface of fine aggregate. Therefore, coal gangue fine aggregate in ICP ion dissolution test mainly consider the surface reaction, without regard to aggregate the internal components, the active change rule with the increase of calcination temperature, is first increases then decreases, peaked at $700{ }^{\circ} \mathrm{C}$.

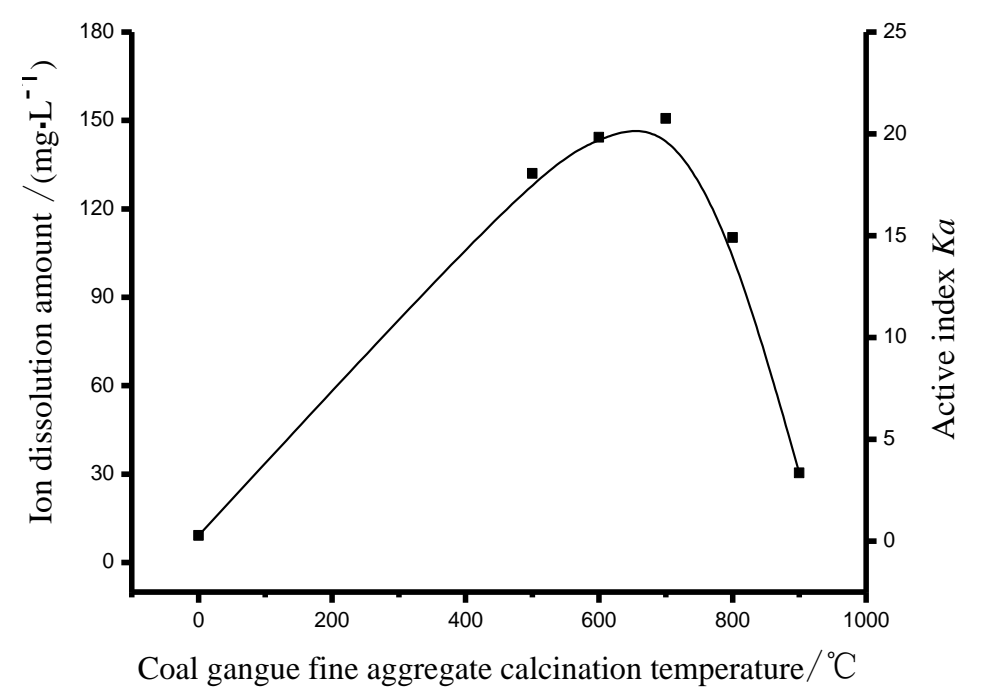

Fig.2 Same fineness modulus of 2.7 ion dissolution regularity of coal gangue fine aggregate

\subsection{Relationship between activity of fine aggregate and fineness modulus of coal gangue}


Through the above analysis, the most active volcanic ash, $\mathrm{Si}^{4+}$ and $\mathrm{Al}^{3+}$ ions when dissolved highest coal gangue fine aggregate calcined at $700{ }^{\circ} \mathrm{C}$. Therefore, this paper selects the different fineness modulus 1.9, 2.7 and 3.4 coal gangue fine materials after calcination at a high temperature of $700{ }^{\circ} \mathrm{C}$, analysis the $\mathrm{Si}^{4+}$ and $\mathrm{Al}^{3+}$ ion dissolution of the relationship between the amount and fineness modulus, as shown in Figure 3. And the $\mathrm{Si}^{4+}$ and $\mathrm{Al}^{3+}$ ion dissolution amount of coal gangue fine aggregate and its surface area ratio, that is, the activity index $K a$, is shown in the right longitudinal coordinates, the variation of the activity index $K a$ and the calcination temperature is observed.



Fig.3 Different fineness modulus of ion dissolution regularity of coal gangue fine aggregate

Figure 3 shows the results of gangue fine aggregate $\mathrm{Si}^{4+}$ and $\mathrm{Al}^{3+}$ ion leaching and the increased $\mathrm{Ka}$ activity index with the gradual reduction of the increasing fineness modulus. The figure also presents the decline in the law between them. Such a phenomenon is caused mainly by the gangue minerals in the calcination process transformation with the same stage and the same chemical environment. However, the coal-fired surface chemical reaction fully occurs when the gangue fineness modulus is small. The gas and steam left a large spill and filled the aggregate surface with interconnected pores. This condition facilitates a full reaction in the ICP ion 
dissolution test and significantly increases its $\mathrm{Si}^{4+}$ and $\mathrm{Al}^{3+}$ ion leaching. Given that the $\mathrm{Si}^{4+}$ and $\mathrm{Al}^{3+}$ ions are only dissolved in the fine aggregate surface, the fineness modulus is smaller than the surface area of the aggregate when the gangue fineness modulus is larger (Table 2).

Therefore, the values of the ion concentration and activity index $K a$ dissolution are higher in the small aggregate fineness modulus (Figure 3). A larger fineness modulus corresponds to lower ion concentration and $K a$ dissolution values.

\subsection{Reaction mechanism of coal gangue calcination and ICP ion dissolution test}

When coal gangue is in the process of high-temperature calcination, it needs to absorb a large amount of energy in the process that is used to fracture alumina octahedral and depolymerization silicon oxygen tetrahedron because the surface of kaolinite is decomposed into kaolinite and water. The free water surface evaporation takes away a significant amount of heat and gas overflow, which means that the coal gangue fine aggregate surface temperature is lower than the calcination temperature and internal temperature [29]. Moreover, the reduction of the aggregate hindered the decomposition of internal mineral composition and the formation of new substances, the internal minerals in the case show their inability to obtain enough energy and ability to sharply reduce the degree of depolymerization. Furthermore, given the increased surface free material, the empty space of the fine aggregate surface is filled, the oxygen is produced externally, and carbon dioxide is not released internally. Calcined coal gangue fine aggregate color tends to be dark inside and the surface color tends to be red because the aggregate in the internal reaction is insufficient, in the process of coal gangue fine aggregate calcination, the surface chemical reaction equation is as follows [23, 30, 31]:

$$
\mathrm{FeCO}_{3} \rightarrow \mathrm{FeO}+\mathrm{CO}_{2}
$$




$$
4 \mathrm{FeO}+\mathrm{O}_{2} \rightarrow 2 \mathrm{Fe}_{2} \mathrm{O}_{3}
$$

$$
\mathrm{Al}_{2} \mathrm{O}_{3} \cdot 2 \mathrm{SiO}_{2} \cdot 2 \mathrm{H}_{2} \mathrm{O} \rightarrow \mathrm{Al}_{2} \mathrm{O}_{3} \cdot 2 \mathrm{SiO}_{2}+2 \mathrm{H}_{2} \mathrm{O}
$$

Coal gangue fine aggregate in the ICP ion dissolution test is mainly silicon oxygen tetrahedron, and the process is alumina tetrahedron depolymerization [32, 33, 34, 35].

$$
\mathrm{Al}-\mathrm{Si}+\mathrm{OH}^{-}(\mathrm{aq}) \rightarrow \mathrm{Al}(\mathrm{OH})_{4}^{-}+\mathrm{OSi}(\mathrm{OH})_{3}
$$

In the ICP ion dissolution test, $\mathrm{Si}^{4+}$ and $\mathrm{Al}^{3+}$ ion leaching depends on the $\mathrm{OH}^{-}$ aluminosilicate material surface reactions, that is, the $\mathrm{OH}^{-}$ions in the alkali metal $\mathrm{Na}^{+}$ electrostatic interaction, electrostatic repulsion, and the $\mathrm{Si}^{4+}$ and $\mathrm{Al}^{3+}$ ion release. The gangue fine aggregate surface has more active $\mathrm{Al}_{2} \mathrm{O}_{3}$ and $\mathrm{SiO}_{2}$ that fully reacts with the solution $\mathrm{OH}^{-}$. The surface of the active material decreases with the further progress of the reaction, and the reaction depth continues to increase. The coal gangue material does not react to the solution of the $\mathrm{OH}^{-}$ ions for the gangue interior impediment. The solution is to increase the pressure and reaction temperature and decrease the diffusion depth, leading to the decrease of the ion diffusion coefficient and the reduction of response capacity [23, 29]. Thus, in the ICP ion elution test, the chemical reactions occur only in generally fine aggregate surface, and the inner portion is not considered.

\subsection{Microstructure of different fineness modulus of fine aggregate mortar}

Given the higher activity index of $K a$ gangue fine aggregate, the active ingredient per unit surface area of $\mathrm{Al}_{2} \mathrm{O}_{3}$ and $\mathrm{SiO}_{2}$ also increases. Thus, in the extent of its occurrence and cement hydration reaction, a higher number corresponds to more hydration products. Therefore, a different fineness modulus with the same calcination temperature $\left(700{ }^{\circ} \mathrm{C}\right)$ for $28 \mathrm{~d}$ in hydration products of fine aggregate mortar SEM diagram was taken to further analyze the different 
fineness modulus of calcined coal gangue fine aggregate and the relationship between the activity index of $K a$ (Figure 4).

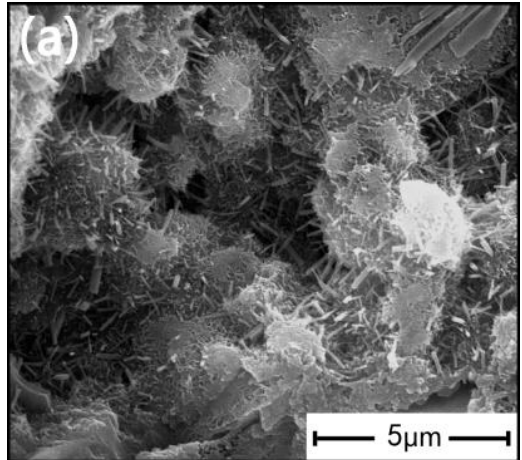

Fineness modulus 1.9 of $3 \mathrm{~d}$ Hydration

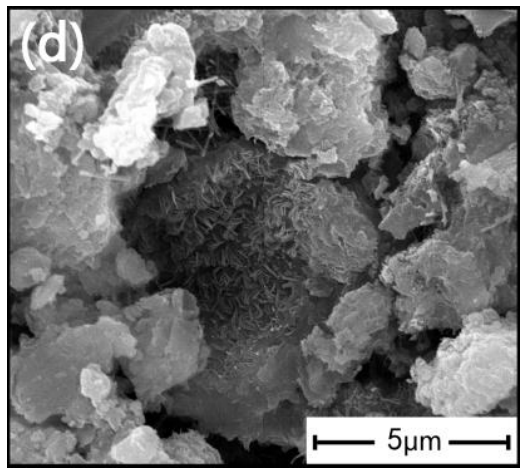

Fineness modulus 2.7 of $3 \mathrm{~d}$ Hydration

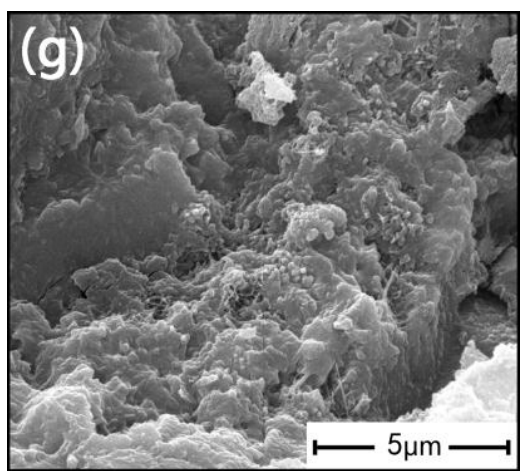

Fineness modulus 3.4 of $3 \mathrm{~d}$ Hydration

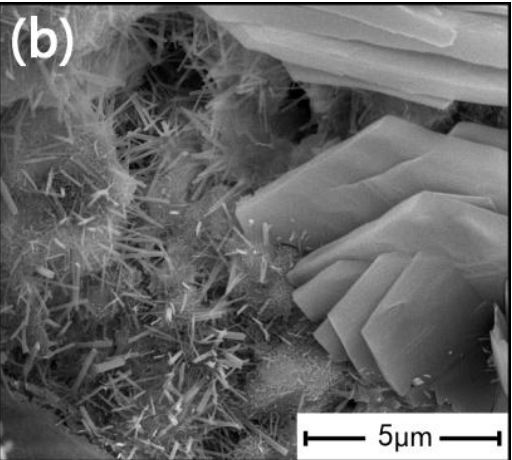

Fineness modulus 1.9 of $7 \mathrm{~d}$ Hydration

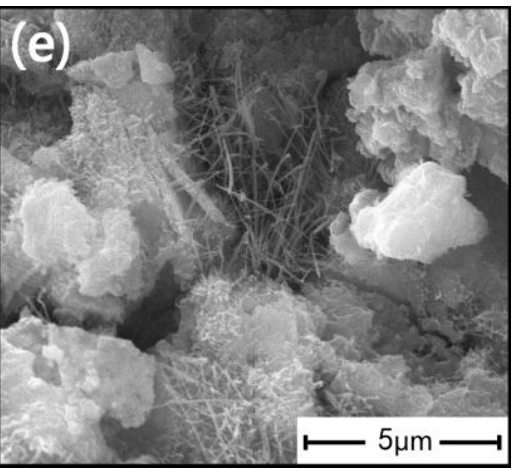

Fineness modulus 2.7 of $7 \mathrm{~d}$ Hydration

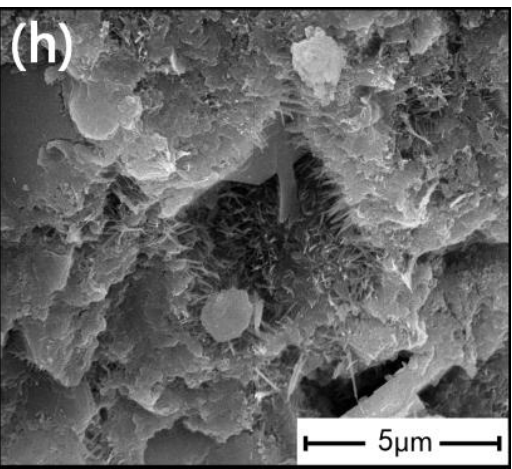

Fineness modulus 3.4 of $7 \mathrm{~d}$ Hydration

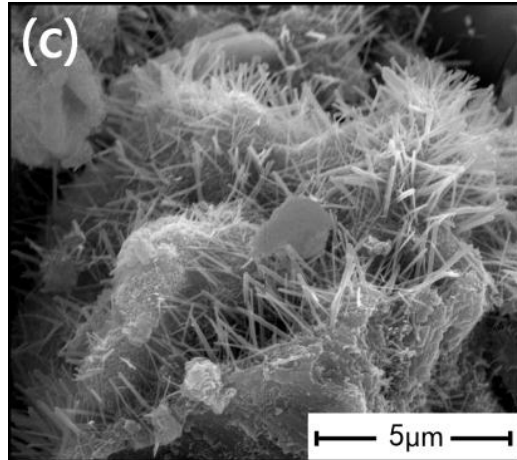

Fineness modulus 1.9 of $28 \mathrm{~d}$ Hydration

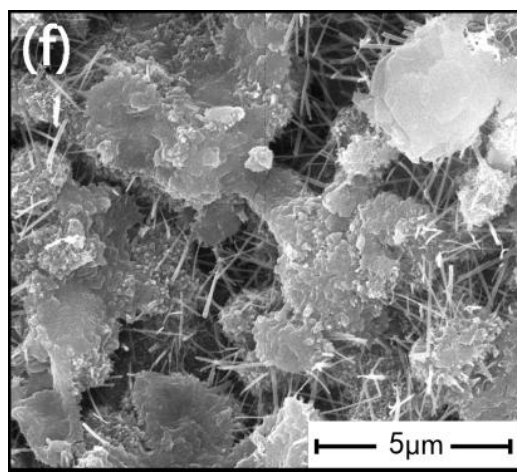

Fineness modulus 2.7 of $28 \mathrm{~d}$ Hydration

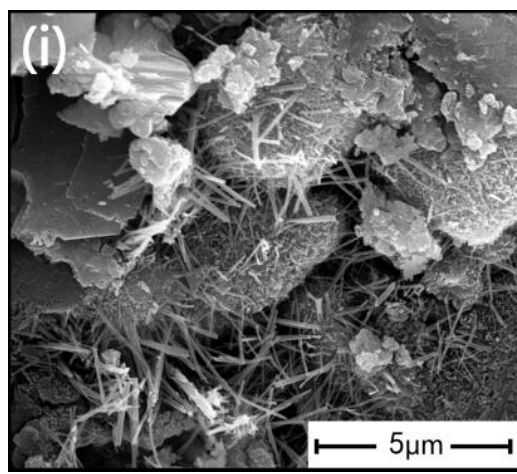

Fineness modulus 3.4 of $28 \mathrm{~d}$ Hydration

Fig.4 Each curing period of Hydration SEM photograph in different fineness modulus of fine aggregate mortar. (a) Fineness modulus 1.9 of 3 d Hydration, (b) Fineness modulus 1.9 of 7 d Hydration, (c) Fineness modulus 1.9 of 28 d Hydration, (d) Fineness modulus 2.7 of 3 d Hydration, (e) Fineness modulus 2.7 of 7 d Hydration, (f) Fineness modulus 2.7 of $28 \mathrm{~d}$ Hydration, (h) Fineness modulus 3.4 of 3 d Hydration, (i) Fineness modulus 3.4 of 7 d Hydration, (j) Fineness modulus 3.4 of 28 d Hydration. 
The SEM image material mortar hydrates comparatively analyzes the different ages of gangue fine sets of different degrees of fineness. When the fineness modulus has a smaller mortar, it has a high degree of hydration. Other large mortars with hydration products in larger quantities show a large number of coal gangue fine aggregate surface chemical reaction. The fine aggregate significantly affects ash. It also shows that calcined coal gangue fine aggregate cement occurs in an environment based on surface chemical reaction.

In the SEM image, a smaller fineness modulus of hardened cement mortar corresponds to more hydration products that were flocculent filling in the microscopic pores of cement mortar. The cement structure is more compact that the hydration process forms a relatively complete network structure, making the structure more homogeneous slurry cement and strengthening the interface structure to improve the pore structure of mortar. The fineness modulus of more hardened cement mortar hydration products is relatively small. The fine aggregate surface in granular form increases its presence. More holes cannot be connected to the organizational structure of an integrated whole. The poor interface results in the low strength of the hardened cement mortar.

\subsection{Different fineness modulus of fine aggregate mortar strength}

The same calcination temperature in the analysis, a smaller fineness modulus of fine aggregate calcined coal gangue and its activity index $K a$ correspond to larger fine aggregate active ingredients in the $\mathrm{Al}_{2} \mathrm{O}_{3}$ and $\mathrm{SiO}_{2}$ unit surface area that is involved in cement hydration reaction. The macro result is the ultimate expression of the strength of the hardened cement mortar compared with the fineness modulus large mortar.

Therefore, through the standard curing in 3, 7, and 28 days calcined at $700{ }^{\circ} \mathrm{C}$, gangue fine 
aggregate mortar strength tests verify the relationship between the firing gangue further fine aggregate activity index $K a$ and fineness modulus. The fineness modulus of 1.9, 2.7, and 3.4 calcined coal gangue fine aggregate mortar age with compressive and flexural strengths is shown in Figure 5.

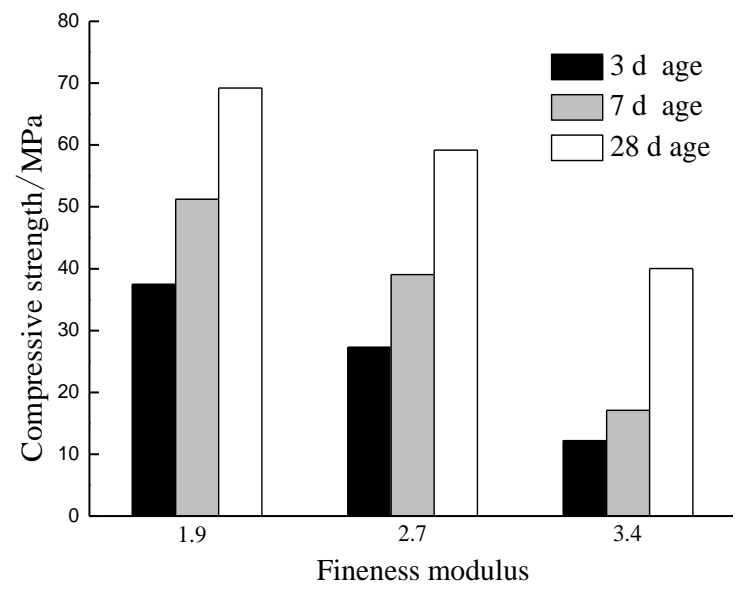

(a) Compressive strength/Mpa

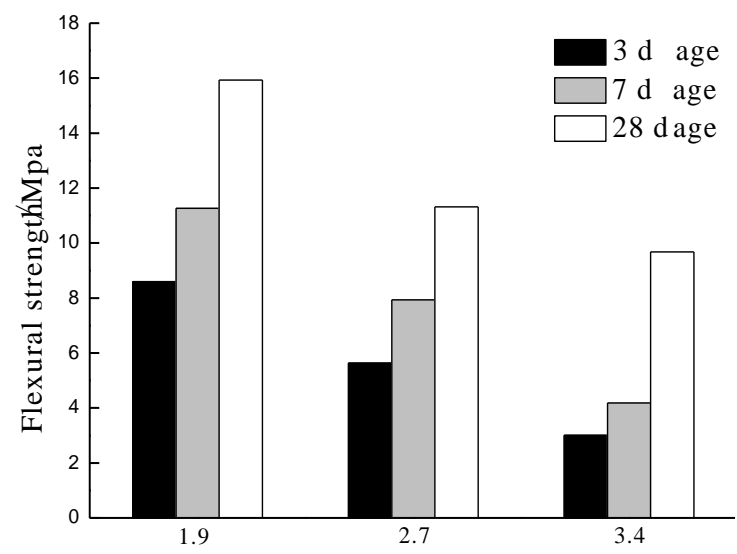

Fineness modulus

(b) Flexural strength/Mpa

Fig.5 Each curing age compressive strength and flexural strength of different fineness modulus of fine aggregate mortar

The fineness modulus with a smaller gangue fine aggregate mortar, compressive strength, and flexural strength of each age has higher values than the fineness modulus with greater fine aggregate mortar. The reason is that the fineness modulus of fine aggregate small coal gangue and its large activity index value, $\mathrm{Ka}$, and ICP ion release similar tests. The hydration reaction that occurs in fine aggregate in cement is an active part of its surface. Thus, their participation in a high degree of cement hydration reaction can generate more hydration products with the surrounding gel product firmly bonded as one. The microstructure of the hardened cement mortar can be improved to decrease the porosity of cement. The strength of the mortar is improved to achieve greater optimization interfacial properties.

From the test results, the fineness modulus of 1.9 gangue fine aggregate mortar, compressive 
strength, and flexural strength for three days were compared with the fineness modulus of $2.7,3.4$ with the mortar increased by $27 \%, 67 \%$ and $35 \%, 65 \%$; compressive strength and flexural strength for seven days, compared with fineness modulus of 2.7, 3.4 with the mortar increased by 24\%, 67\% and 30\%, 63\%; and 28 days compressive strength and flexural strength, compared with fineness modulus of 2.7, 3.4 mortar increased by 15\%, 42\% and 29\%, 39\%. As shown in Figure 5, a smaller fineness modulus of fine aggregate mortar gangue early age compressive strength and flexural strength faster than fineness modulus with a significant increase of mortar. The mortar shows significant early strength characteristics.

\section{Conclusions}

To promote calcined coal gangue fine aggregate used in concrete mortar engineering, an ICP ion dissolution test was conducted on constructed calcined coal gangue fine aggregate $\mathrm{Si}^{4+}$ and $\mathrm{Al}^{3+}$ ion, leaching the ratio of the sum of its surface area as an active quantitative evaluation, activity index $(\mathrm{Ka})$. The analysis of the XRD of calcined coal gangue fine aggregate and the chemical reaction mechanism analysis verified the accuracy and rationality of active quantitative indicators. In the same calcination temperature and surface area of coal gangue fine aggregate with the same ion dissolution ability, the activity of coal gangue fine aggregate index increases as the fineness modulus decreases gradually. On the basis of a different fineness modulus, different curing ages of concrete mortar compressive strength and flexural strength test, and a combination of hardened cement mortar microscopic test and analysis, the test results show that a higher activity index of coal gangue fine aggregate mortar correspond to higher compressive strength and flexural strength. Moreover, the macro mechanical performance of concrete mortar is improved, and the early strength of concrete mortar shows clear characteristics. 


\section{Acknowledgements}

This study has been partially funded by the National Science Foundation Project "Overall stabilization mechanism in mining area bridge structure" (51274192), the State of Housing and Urban-Rural Development of Science and Technology Project "Durability research and numerical simulation of defects gangue green concrete" (2013-K4-40), the State Administration of Work Safety Science and Technology Project "Durability Assessment of damage theory based on high and steep concrete slope protection" (2012-173), and the Jiangsu Province Graduate Student Training Innovation Project "Effects of chlorine ion permeability gangue mechanical damage resistance of concrete" (CXZZ12-0937).

\section{References}

[1] X.M. Duan, J.W. Xia, J.P. Yang, Influence of coal gangue fine aggregate on microstructure of cement mortar and its action mechanism, Jianzhu Cailiao Xuebao. 17(2014)700-705.

[2] N. Zhang, H.H. Sun, X.M. Liu, J.X. Zhang, Early-age characteristics of red mud-coal gangue cementitious material, J. Hazard. Mater. 167(2009)927-932.

[3] S.X. Zhou, S.M. Huang, Effect of two kinds of activated coal gangue powder on compressive strength and pore size of blended cement mortars, Disaster Adv. 3(2010)397-399.

[4] D. Wu, B.G. Yang, Y.C. Liu, Pressure drop in loop pipe flow of fresh cemented coal gangue-fly ash slurry: Experiment and simulation, Adv. Powder Technol. 26(2015)920-927.

[5] H.J. Wu, L.D. Wang, Shape effect of microstructured $\mathrm{CeO}_{2}$ with various morphologies on CO catalytic oxidation, Catal. Commun. 12(2011)1374-1379. 
[6] F. Salguero, J.A. Grande, T. Valente, R. Garrido, M.L. De la Torre, J.C. Fortes, A. Sánchez, Recycling of manganese gangue materials from waste-dumps in the Iberian Pyrite Belt-Application as filler for concrete production, Constr. Build. Mater. 54(2014)363-368.

[7] B.Z. Zhu, Y.L. Sun, C.W. Xie, Spectroscopy research on the Guizhou Xingyi gangue of different calcined temperatures, Meitan Xuebao. 33(2008)1049-1052.

[8] V. Podgursky, V. Rose, J. Costina, R. Franchy, Step flow observed on top of oxidized Coal(1 0 0) surface, Appl. Surf. Sci. 253(2006)1796-1800.

[9] Y.F. Li, W.X. Wang, X.Y. Yang, Analysis of thermal activation and phase transformation of coal-gangue, Kuei Suan Jen Hsueh Pao. 35(2007)1258-1263+1269.

[10] Z.H. Sun, K.P. Liu, M.Q. Wang, Z.M. Wang, F.P. Yang, Study on activation properties of spontaneous coal gangue, Jianzhu Cailiao Xuebao. 16(2013)497-502.

[11] Y. Y Zhang, L. Xu, S. Seetharaman, L.L. Liu, X.D. Wang, Z.T. Zhang, Effects of chemistry and mineral on structural evolution and chemical reactivity of coal gangue during calcination: towards efficient utilization, Mater. Struct. 48(2015)2779-2793.

[12] X.M. Duan, J.W. Xia, J.C. Cao, F.Z. Yang, Experimental research on the influence of coal gangue aggregate-cement-based materials on the mechanical properities under different curing conditions, Concrete. 2(2014)75-78.

[13] X. M. Liu, N. Zhang, Y. Yao, H. H. Sun, H. Feng, Micro-structural characterization of the hydration products of bauxite-calcination-method red mud-coal gangue based cementitious materials, J. Hazard. Mater. 262(2013)428-438.

[14] X. Y. Song, C.C. Gong, D. X. Li, Study on structural characteristics and mechanical property of coal gangue in activation process, Kuei Suan Jen Hsueh Pao. 32(2004)358-363. 
[15] D.W. Golightly, A. Montaser, B. L. Smith, A.F. Jr Dorrzapf, Spark ablation-inductively coupled plasma spectrometry for analysis of geologic materials, Talanta 36(1989) 299-303.

[16] Standards China. GB/T19587-2004: determination of the specific surface area of solids by gas adsorption using the BET method. Beijing; 2009.

[17] Standards China. JGJ52-2006: standard for technical requirements and test method of sand and crushed stone (or gravel) for ordinary concrete. Beijing; 2006

[18] Standards China. GB/T14684-2011: sand for construction. Beijing; 2011.

[19] Standards China. GB/T14685-2011: pebble and crushed stone for construction. Beijing; 2011.

[20] T.K. Erdem, C. Meral, M. Tokyay, T.Y. Erdoğan, Use of perlite as a pozzolanic addition in producing blended cements, Cem. Corcr. Compos. 29(2007)13-21.

[21] M. P. Mateo, G. Nicolas, A. Yañez, Characterization of inorganic species in coal by laser-induced breakdown spectroscopy using UV and IR radiations, Appl. Surf. Sci. 254(2007)868-872.

[22] W. Guo, D.X. Li, J.H. Chen, N.R. Yang, Rapid evaluation method of the pozzolanic reactive activity of coal gangue, Kuei Suan Jen Hsueh Pao. 35(2007)489-494.

[23] H.J. Li, Comprehensive utilization of coal gangue, Chemical Industry Press, Beijing, 2010.

[24] C.S. Zhang, Pozzolanic activity of burned coal gangue and its effects on structure of cement mortar, J. Wuhan Univ. Technol. Mater. Sci. Ed. 21(2006)150-153.

[25] D. X. Li, X.Y. Song, C.C. Gong, Z.H. Pan, Research on cementitious behavior and 
mechanism of pozzolanic cement with coal gangue, Cement Concrete Res. 36(2006)1752-1759.

[26] Standards China. JGJ/T70-2009: standard for test method of performance on building mortar. Beijing; 2009.

[27] W. Guo, Research on coal gangue activation and its activity evaluation method [Ph.D. dissertation]. Nanjing University of Technology; 2005.

[28] J. X. Zhang, H.H. Sun, J.H. Wan, Z.L. Yi, Study on microstructure and mechanical property of interfacial transition zone between limestone aggregate and sialite paste, Constr. Build. Mater. 23(2009)3393-3397.

[29] C.S. Zhang, New technology of comprehensive utilization of coal gangue, Chemical Industry Press, Beijing, 2008.

[30] H.J. Li, H.H. Sun, X.C. Tie, X.J. Xiao, A new method to evaluate the hydraulic activity of Al-Si materials, Sci. China Ser. E Technol. Sci. 51(2008)113-120.

[31] H. J. Li, H.H. Sun, X.C. Tie, X.J. Xiao, Dissolution properties of calcined gangue, J. Univ. Sci. Technol. Beijing Eng. Ed. 13(2006)570-576.

[32] M. Misz-Kennan, M.J. Fabiańska, Application of organic petrology and geochemistry to coal waste studies, Int. J. Coal Geo. 88(2001)1-23.

[33] Y. Zhang, X.J. Yang, L.Y. Guo, C. Han, T.P. Zhou, Research on dissolution characteristics of coal gangue immersed in different acid solutions, Jianzhu Cailiao Xuebao. 17(2014)326-330.

[34] Z.J. Xu, Z.H. Dai, J. Ni, Structures of coal (llll) surface: a first principles study, Appl. Surf. Sci. 257(2011)3341-3345. 
[35] H.J. Li, H.H. Sun, X.C. Tie, Coordination of Si and Al in the thermal activation and gelatification of gangue, Qinghua Daxue Xuebao. 46(2006)2015-2018. 